\title{
Southern Ocean Heat Storage, Reemergence, and Winter Sea Ice Decline Induced by Summertime Winds $\mathscr{O}$
}

\author{
Edward W. Doddridge, ${ }^{\mathrm{a}, \mathrm{b}}$ John Marshall, ${ }^{\text {a }}$ Hajoon Song, ${ }^{\mathrm{c}}$ JeAn-Michel CAmpin, ${ }^{\mathrm{a}}$ \\ AND MAXWELL KELLEY ${ }^{\text {d }}$ \\ ${ }^{a}$ Earth, Atmospheric and Planetary Sciences, Massachusetts Institute of Technology, Cambridge, Massachusetts \\ ${ }^{\mathrm{b}}$ Australian Antarctic Program Partnership, Institute for Marine and Antarctic Studies, University of Tasmania, Hobart, Australia \\ ${ }^{\mathrm{c}}$ Department of Atmospheric Sciences, Yonsei University, Seoul, South Korea \\ ${ }^{\mathrm{d}}$ NASA Goddard Institute for Space Studies, New York, New York
}

(Manuscript received 7 May 2020, in final form 29 October 2020)

\begin{abstract}
The observational record shows a substantial 40-yr upward trend in summertime westerly winds over the Southern Ocean, as characterized by the southern annular mode (SAM) index. Enhanced summertime westerly winds have been linked to cold summertime sea surface temperature (SST) anomalies. Previous studies have suggested that Ekman transport or upwelling is responsible for this seasonal cooling. Here, another process is presented in which enhanced vertical mixing, driven by summertime wind anomalies, moves heat downward, cooling the sea surface and simultaneously warming the subsurface waters. The anomalously cold SSTs draw heat from the atmosphere into the ocean, leading to increased depth-integrated ocean heat content. The subsurface heat is returned to the surface mixed layer during the autumn and winter as the mixed layer deepens, leading to anomalously warm SSTs and potentially reducing sea ice cover. Observational analyses and numerical experiments support our proposed mechanism, showing that enhanced vertical mixing produces subsurface warming and cools the surface mixed layer. Nevertheless, the dominant driver of surface cooling remains uncertain; the relative importance of advective and mixing contributions to the surface cooling is model dependent. Modeling results suggest that sea ice volume is more sensitive to summertime winds than sea ice extent, implying that enhanced summertime westerly winds may lead to thinner sea ice in the following winter, if not lesser ice extent. Thus, strong summertime winds could precondition the sea ice cover for a rapid retreat in the following melt season.
\end{abstract}

KEYWORDS: Sea ice; Southern Ocean; Mixing; Atmosphere-ocean interaction; Oceanic mixed layer; Sea surface temperature

\section{Introduction}

Each year approximately 15 million $\mathrm{km}^{2}$ of sea ice forms and subsequently melts in the seasonal ice zone of the Southern Ocean (Fetterer et al. 2017). The buoyancy fluxes associated with this seasonal ice cycle play an important role in the meridional overturning circulation in the Southern Ocean (Abernathey et al. 2016; Haumann et al. 2016). This circulation connects the surface with the abyss and is a conduit for exchange between reservoirs of heat, carbon, and nutrients in the ocean and the atmosphere (Sarmiento et al. 2004). To predict how the climate system will respond to anthropogenic influences we need to be able to capture changes to the overturning circulation, which itself demands understanding of the processes that affect the seasonal growth and decay of sea ice in the Southern Ocean.

Sea ice extent around Antarctica has exhibited a gradual increase from the beginning of the satellite record in the late 1970s. This is likely to be causally linked to the strengthening of the surface westerlies blowing around Antarctica during the

Supplemental information related to this paper is available at the Journals Online website: https://doi.org/10.1175/JCLI-D-200322.s1.

Corresponding author: Edward W. Doddridge, edward.doddridge@ utas.edu.au same period. As described by, for example, Ferreira et al. (2015), Purich et al. (2016), Doddridge and Marshall (2017), and Kostov et al. (2017), the enhanced summertime westerly winds associated with the positive phase of the SAM lead to a rapid cooling of the SST on a time scale of weeks to months. Multiple mechanisms have been proposed to explain the SST response. Seviour et al. (2017) used a global coupled model to show that a shift in the location of clouds over the Southern Ocean results in reduced incoming shortwave radiation and increased freshwater fluxes into the ocean, which contribute to cooling the SST. Other studies have focused on ocean dynamics, with horizontal and vertical advection both being invoked to explain the cooling associated with a positive summertime SAM: Ferreira et al. (2015) and Kostov et al. (2017) focused on anomalous northward Ekman transport moving fluid across the meridional temperature gradient, while Purich et al. (2016) suggested that the cooling was caused by anomalous Ekman suction drawing cold subsurface water upward into the mixed layer. In contrast to these two advective mechanisms, Doddridge et al. (2019) suggested that enhanced near surface vertical mixing in the summertime may contribute to the cold surface anomalies by mixing surface heat to depth, simultaneously creating anomalously warm temperatures just below the zonal-mean mixed layer depth. In an observational study, Doddridge and Marshall (2017) showed that cold summertime SST anomalies associated with a positive summertime SAM lead to enhanced growth of sea ice in the autumn. Their results suggested that there may also be a small reduction in sea ice extent at the 


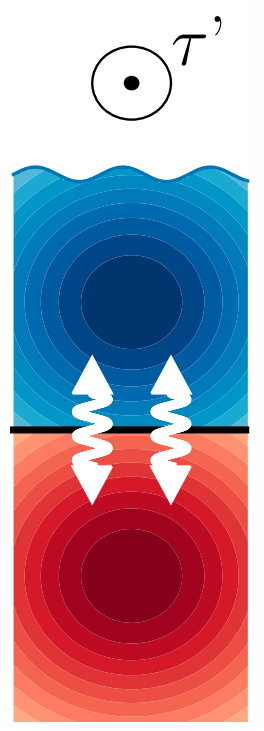

Summer
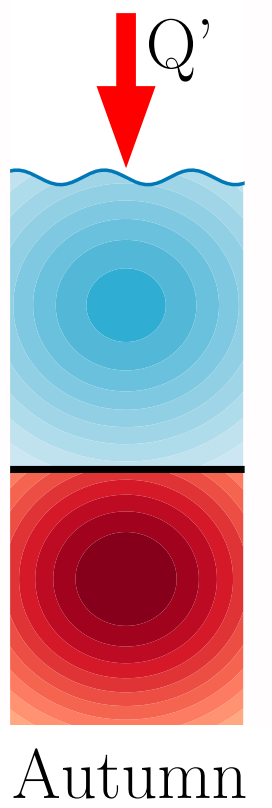
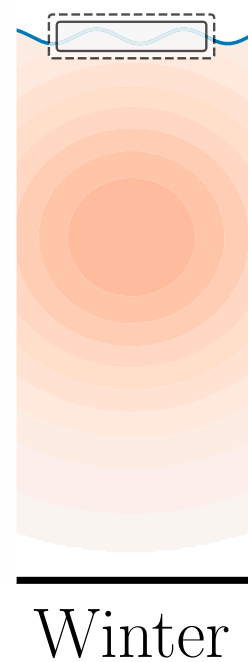

FIG. 1. Schematic of vertical mixing/heat sequestration mechanism. (left) In summer, anomalous westerly winds $\left(\tau^{\prime}\right)$ enhance vertical mixing at the base of the mixed layer (white squiggly arrows and horizontal black line, respectively) moving heat downward and causing a vertical dipole of anomalous temperatures (colors). (center) The anomalously cold SST causes anomalous heat fluxes into the ocean during the autumn ( $Q^{\prime}$ and red arrow), which reduces the cold SST anomaly. As autumn progresses, the mixed layer continues to deepen, entraining the anomalously warm fluid sequestered below the zonal-mean mixed layer depth. Due to the anomalous surface heat fluxes, which increase the total heat content of the upper ocean, the mixed layer is now anomalously warm. (right) This is expected to lead to a reduction in wintertime sea ice, as shown schematically by the reduction in volume between the dashed outline and the solid outline.

wintertime maximum. However, substantial interannual variability and a relatively short observational record prevented the identification of a statistically significant signal in wintertime sea ice extent. Motivated by the observational analysis of Doddridge and Marshall (2017) and the enhanced mixing reported by Doddridge et al. (2019), we return to these themes in this paper.

As summarized in Fig. 1, we propose a vertical-mixing mechanism in which summertime wind anomalies sequester heat below the mixed layer and cool the surface. As the mixed layer deepens in the autumn and winter, this heat sequestered in the summer reemerges, warming SSTs, reducing sea ice volume and potentially sea ice cover. Our focus on summertime winds is motivated by the observed changes in the summertime SAM (Marshall 2003), and the potential for seasonal reemergence of the sequestered heat. During winter the mixed layer is substantially deeper (Holte et al. 2017), and the stratification is such that additional mixing at the base of the mixed layer would cool the subsurface waters. It is only during the summer, when a shallow thermally stratified layer forms a cap above the previous winter's mixed layer, that additional mixing can store heat in the subsurface ocean. We have therefore focused on the impacts of enhanced zonal winds in the summertime.
We now set out to explore these ideas in the observations, in an idealized channel model of the seasonal ice zone, and in a comprehensive coupled climate model.

Our paper is set out as follows. In section 2 we describe the climatology of the Southern Ocean and present our new mechanism. In section 3 we analyze observational datasets and find some evidence to support our new mechanism. In an effort to reduce the uncertainties in our analysis we turn to numerical models in sections 4 and 5, where we find strong evidence that enhanced summertime winds lead to increased vertical mixing and the subsurface sequestration of heat. We then summarize our findings and present our conclusions in section 6 .

\section{Vertical mixing and the seasonal sequestration of heat}

The time-mean circulation of the extratropical atmosphere in the Southern Hemisphere is dominated by a strong westerly jet over the Southern Ocean (Fig. 2a). Surface winds are the major source of energy for the oceanic circulation (Wunsch 1998) and contribute substantially to mixing (Munk and Wunsch 1998), including to the formation of the surface mixed layer (Pollard et al. 1972; Wunsch and Ferrari 2004). The variability of the atmospheric circulation in the Southern Hemisphere is dominated by the SAM (Gong and Wang 1999; Thompson and Wallace 2000). The positive phase of the SAM is associated with a strengthening and poleward shift of the midlatitude westerly winds (Thompson and Wallace 2000). Both the summertime and annual mean SAM have become increasingly positive since the middle of the twentieth century (Jones et al. 2016; Marshall 2003) (Fig. 2b) due to anthropogenic emissions of ozone depleting substances and greenhouse gases (see e.g., Polvani et al. 2011; Swart and Fyfe 2012; Thompson et al. 2011).

The positive trend in the SAM over the latter part of the twentieth century (Jones et al. 2016) has contributed to an increase in wind stress variance and more near inertial energy in the Southern Ocean (Rath et al. 2014). This near inertial wind stress variability has a large impact on the circulation of the Southern Ocean (Munday and Zhai 2017) and generates near-inertial waves that increase mixing in the upper ocean (Furuichi et al. 2008; Rath et al. 2014; Song et al. 2019; Zhai et al. 2009). We should therefore expect that the zonal wind changes associated with the SAM will affect the depth of the surface mixed layer. This intuition is supported by the results of Panassa et al. (2018), who found that the stronger zonal winds associated with the positive phase of the SAM lead to deeper summertime mixed layers in the Southern Ocean.

The Southern Ocean mixed layer serves as a gateway between the subsurface ocean and the atmosphere (Klocker 2018; Marshall 1997) and the seasonal cycle in the depth of the mixed layer regulates a range of physical and biogeochemical processes (Doney et al. 2004; Williams et al. 2017). The Southern Ocean mixed layer is shallowest during the summer months (Holte et al. 2017), when the cold remnants of the previous winter's mixed layer are capped by a warmer surface layer. This thermal structure is crucial for our mechanism, since it supplies a large reservoir of cold water that can be readily accessed by the surface mixed layer. Any process that acts to 

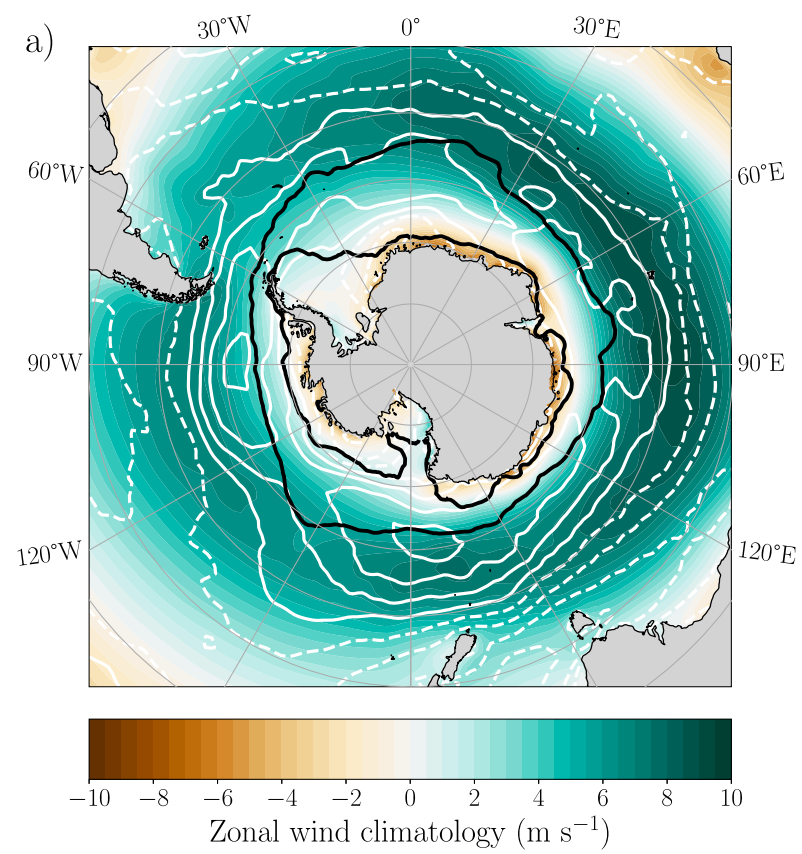

b)

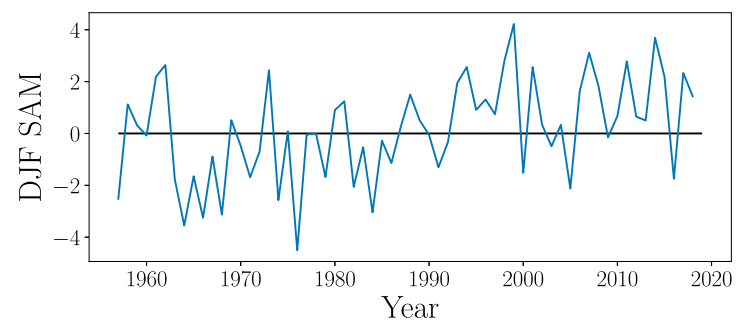

FIG. 2. (a) Climatology of the Southern Ocean. Climatological zonal wind from the ERA-Interim product (Dee et al. 2011) averaged over the period 1979 to 2016 inclusive (colors), wind anomaly associated with a +1 summertime southern annular mode (SAM) anomaly calculated from a linear regression of the summertime SAM index (Marshall 2003) and the ERA-Interim zonal wind field (Dee et al. 2011) (white contours, contour interval is $0.2 \mathrm{~m} \mathrm{~s}^{-1}$, negative contours dashed), and climatological seasonal sea ice edges for the summer minimum (February) and winter maximum (September) from the National Oceanic and Atmospheric Administration Optimum Interpolation sea ice dataset (Banzon et al. 2020) over the period 1981 to 2019 (defined as the $15 \%$ concentration contour, black contours). (b) Observational summertime (December-February) SAM index from Marshall (2003).

deepen the summertime mixed layer will cool the surface waters and warm the fluid that was previously below the base of the summertime mixed layer.

Doddridge et al. (2019) found that stronger westerly winds associated with the positive phase of the SAM created a region of warming just below the zonal-mean mixed layer depth in both observations and models. A heat budget analysis of their simulations showed that this warming was due to enhanced vertical mixing. Since mixing can only redistribute heat, this enhanced vertical mixing must also contribute to the observed surface cooling that has previously been ascribed to purely advective mechanisms (Ferreira et al. 2015; Purich et al. 2016). The presence of anomalously cold water at the sea surface will affect air-sea heat fluxes; if the surface ocean is anomalously cold, then the air-sea heat flux feedback will act to reduce the SST anomaly by transferring heat from the atmosphere into the ocean (Hausmann et al. 2017). We therefore expect an anomalously cold surface ocean to absorb additional heat from the atmosphere, leading to a positive depth integrated ocean heat content anomaly. As the mixed layer deepens during autumn and winter, the subsurface heat will be returned to the surface where it may affect the growth of sea ice and reduce sea ice extent or volume. Our proposed mechanism is summarized schematically in Fig. 1. In the following sections we use observational datasets and numerical experiments to test our proposed mechanism and explore the relationship between the SAM, zonal-mean temperature, and sea ice.

\section{Analysis of the seasonal cycle of Southern Ocean upper-ocean heat storage from Argo data}

We begin by regressing an observational time series of the summertime [December-February (DJF)] SAM (Marshall 2003) against zonal-mean temperature from a gridded Argo product, an extension of the dataset described by Roemmich and Gilson (2009). By comparing the magnitude of the heat content anomalies in the mixed layer and below we may be able to infer the mechanism responsible for cooling the mixed layer. If the two heat content anomalies are of equivalent magnitudes, then we require a mechanism that both cools the surface and warms the subsurface at equivalent rates, which is consistent with enhanced vertical mixing creating the temperature anomalies. However, if the cooling in the mixed layer is much larger than the warming below, then it is likely that advection is the dominant mechanism driving mixed layer temperature changes.

The Argo dataset has monthly temporal resolution, but excludes the seasonal ice zone. Figure 3 a shows the calculated zonal-mean temperature anomaly in February per unit DJF SAM, and clearly exhibits a vertical dipole centered around the February zonal-mean mixed layer depth from Holte et al. (2017). A region of surface warming is also visible to the north of the vertical dipole. This warming occurs where the westerly winds weaken during a positive SAM. The warming could be due either to anomalous southward Ekman transport, or reduced vertical mixing. Our focus here is on the vertical cooling/ warming dipole to the south, and we will not be analyzing the patch of warming to the north. By taking a volumetric integral of these temperature anomalies we can calculate the associated ocean heat content anomaly per unit DJF SAM for both the mixed layer and a $100 \mathrm{~m}$ thick region below the mixed layer (colored boxes in Fig. 3a). As the mixed layer deepens over the seasonal cycle, the volume over which we integrate to calculate the mixed layer heat content anomaly changes. Since the subsurface region is defined as a $100 \mathrm{~m}$ thick layer beginning at the base of the zonal-mean mixed layer, this region moves but its volume remains constant (to within the accuracy of the thin-shell approximation (Vallis 2006)). During the autumn and winter months much of the 


\section{Observations}

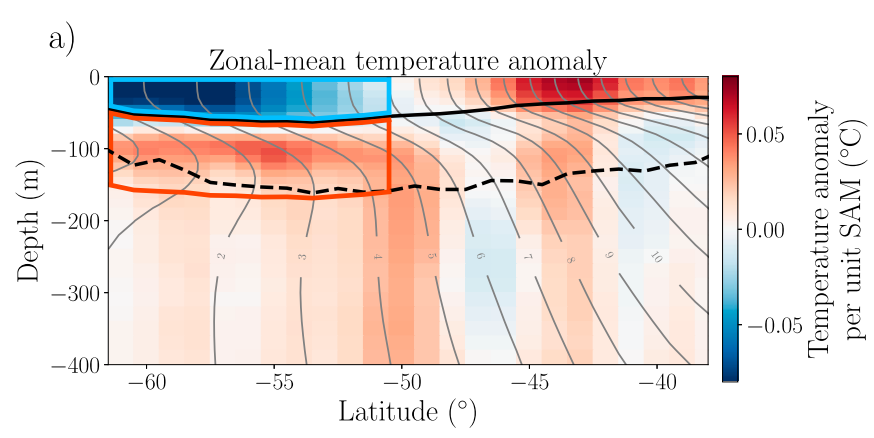

b)

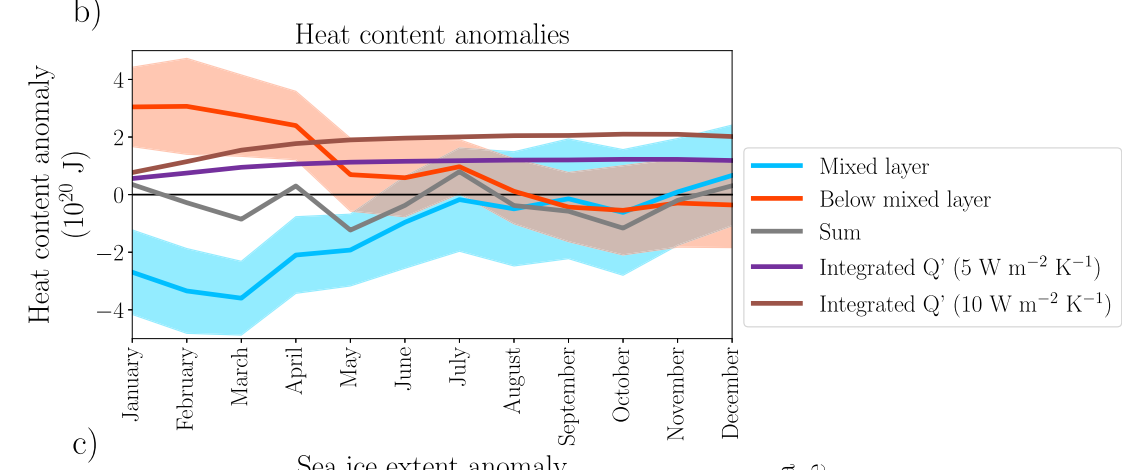

c)

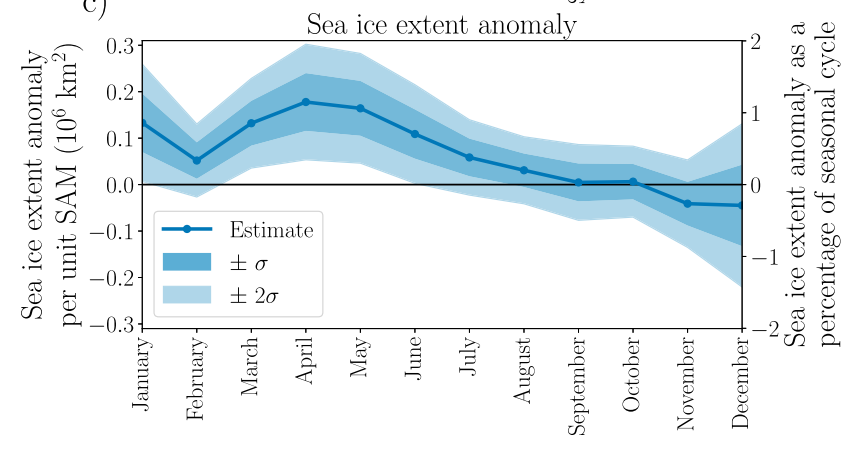

FIG. 3. (a) Zonal-mean temperature anomaly in February per unit DJF SAM from an Argo-derived dataset [an extension of the dataset described in Roemmich and Gilson (2009)]. Also plotted is the climatological zonal-mean ocean temperature in February with a contour interval of $1{ }^{\circ} \mathrm{C}$ (gray contours) and the climatological zonal-mean mixed layer depth in February (solid black line) and September (dashed black line) from Holte et al. (2017). Blue and red boxes represent the regions in which the mixed layer and below mixed layer heat content anomalies are calculated in February. (b) Heat content anomalies per unit DJF SAM [from the Marshall (2003) SAM index] for cooling in the mixed layer (blue) and warming below (red). The colors are matched to the boxes shown in (a). Integrated anomalous surface heat flux estimates for surface heat flux values of 5 and $10 \mathrm{~W} \mathrm{~m}^{-2} \mathrm{~K}^{-1}$ are shown by the purple and brown lines, respectively. (c) Sea ice extent anomaly per unit DJF SAM calculated using detrended time series from the National Snow and Ice Data Center (Fetterer et al. 2017). Shaded regions show \pm 1 - and \pm 2 -sigma error estimate for the regression coefficient. Using the unmodified time series does not qualitatively change the result.

fluid that is initially in our "below mixed layer" region is entrained into the mixed layer.

The ocean heat content anomaly in the mixed layer has approximately the same magnitude as the heat content anomaly in the fluid below the mixed layer. The fact that these two ocean heat content anomalies have roughly equivalent magnitudes, but opposite signs is consistent with our hypothesis that enhanced vertical mixing redistributes heat downward from the surface. The sum of the two heat content anomalies is approximately zero, but the large uncertainty means that we are unable to rule out an advective contribution to the observed cooling in the mixed layer. By considering the evolution of the heat content anomalies we can also assess the evidence for anomalous surface heat fluxes. With an atmospheric damping rate of $5-10 \mathrm{~W} \mathrm{~m}^{-2} \mathrm{~K}^{-1}$ in the Southern Ocean 


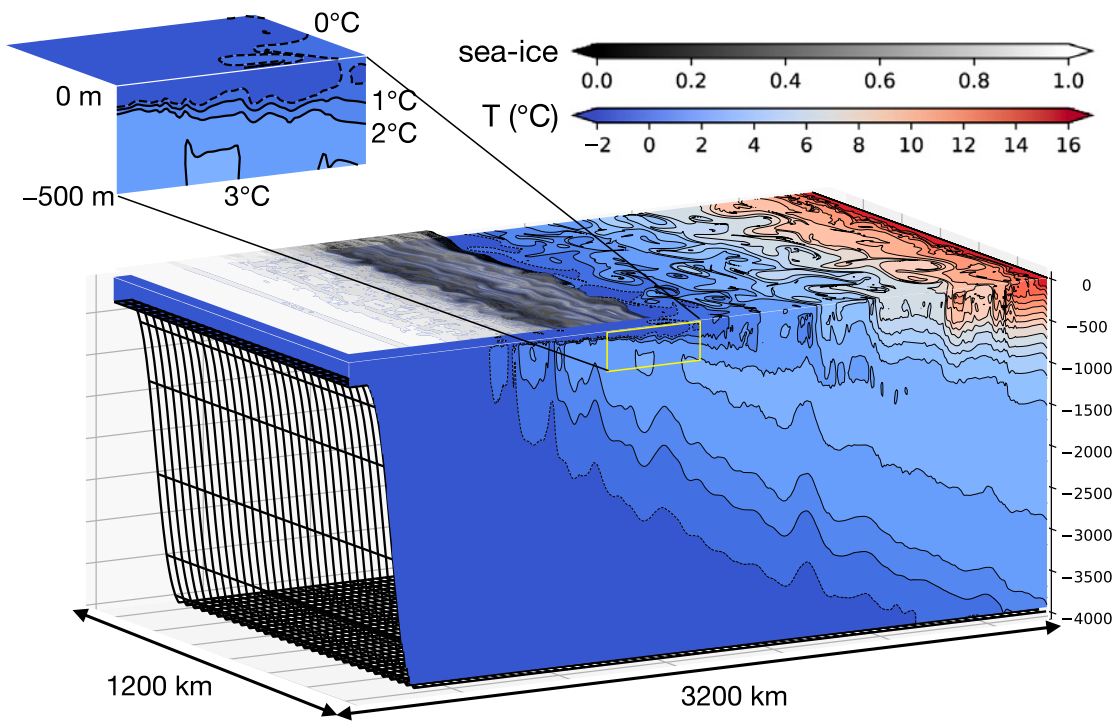

FIG. 4. Snapshot of the temperature and sea ice fields in October (austral spring) from our idealized reentrant eddy-resolving channel model using MITgcm (Marshall et al. 1997a,b). The model is driven by Coordinated Ocean Research Experiments Corrected Normal Year Forcing winds and fluxes. Note the presence of cold freshwater at the surface in the region of the seasonal ice zone and a pronounced temperature inversion below.

(Hausmann et al. 2016), the expected integrated anomalous heat flux into the ocean is within the uncertainty range of our calculated anomalous heat contents (Fig. 3b). This suggests that the expected heat flux signal is too small to be reliably extracted using this methodology and the available data.

The analysis presented by Doddridge and Marshall (2017) (their Fig. 3c) showed a transient increase in sea ice extent due to the summertime SAM. Following Doddridge and Marshall (2017), we use the Sea Ice Index, version 3, produced by Fetterer et al. (2017) to assess sea ice extent and the National Oceanic and Atmospheric Administration (NOAA) Optimal Interpolation, version 2.1, dataset for sea ice concentration and SST (Reynolds et al. 2002; Banzon et al. 2020). Repeating the analysis from Doddridge and Marshall (2017) with the additional data now available does not qualitatively alter the conclusions; the sea ice extent anomaly is largest in April, when the anomaly per unit SAM is equivalent to approximately $1 \%$ of the seasonal cycle in sea ice extent, and then decreases, becoming negative by the end of the year (see Fig. 3c). However, due to the substantial interannual variability we are unable to find evidence supporting the influence of the DJF SAM on wintertime sea ice extent in the observational record.

While our observational analysis is consistent with enhanced vertical mixing driving these zonal-mean temperature anomalies, it is not conclusive. To further explore the driving mechanism behind the observed vertical dipole in anomalous zonal-mean temperature, we turn to numerical models.

\section{Analysis of an idealized channel model of the ACC and its seasonal ice zone}

We now turn to an idealized channel model of the ACC and its seasonal ice zone to further explore the response of the
Southern Ocean to summertime perturbations in the westerly winds. Using a model allows us to diagnose heat budgets and isolate mechanisms driving change. A snapshot of the model state in October (austral spring) is shown in Fig. 4, which clearly highlights the eddying nature of the flow field.

The model is a reentrant channel, $3200 \mathrm{~km}$ wide, $1200 \mathrm{~km}$ long, and $4 \mathrm{~km}$ deep. The bathymetry for this model consists of a $300-\mathrm{m}-$ deep continental shelf at the southern boundary, which then slopes down to a flat bottom at $4000 \mathrm{~m}$ depth for the rest of the domain. The horizontal resolution is $4 \mathrm{~km}$ and so resolves the oceanic mesoscale eddy field, which has been shown to play a leading-order role in the dynamics of the Southern Ocean (see e.g., Marshall and Radko 2003; Marshall and Speer 2012; Munday et al. 2013). The model also has relatively high vertical resolution, which will aid the representation of enhanced near surface mixing. The mixed layer depth in our idealized channel model is calculated using the temperature-based criterion of Kara et al. (2000) with $\Delta T=0.8^{\circ} \mathrm{C}$. Further details of our numerical setup can be found in Doddridge et al. (2019). While our model includes interactive sea ice (Losch et al. 2010) it lacks an interactive atmosphere, which precludes the study of coupled ocean-atmosphere phenomena. We use a repeating seasonal cycle of surface forcings that are derived from the Co-ordinated Ocean-Ice Reference Experiments (CORE) Corrected Normal Year Forcing, version 2.0 (CNYF) (Large and Yeager 2004). The prescribed atmospheric fields are equivalent to an atmosphere with an infinite heat capacity, which means that the heat fluxes into and out of our ocean model are likely to be larger than is realistic.

The MITgcm (Marshall et al. 1997a,b) is used to solve the equations of motion, and the scientific Python stack to analyze the output (Hoyer and Hamman 2017; Hunter 2007; Kluyver et al. 2016; Perez and Granger 2007; Van Der Walt et al. 2011). 


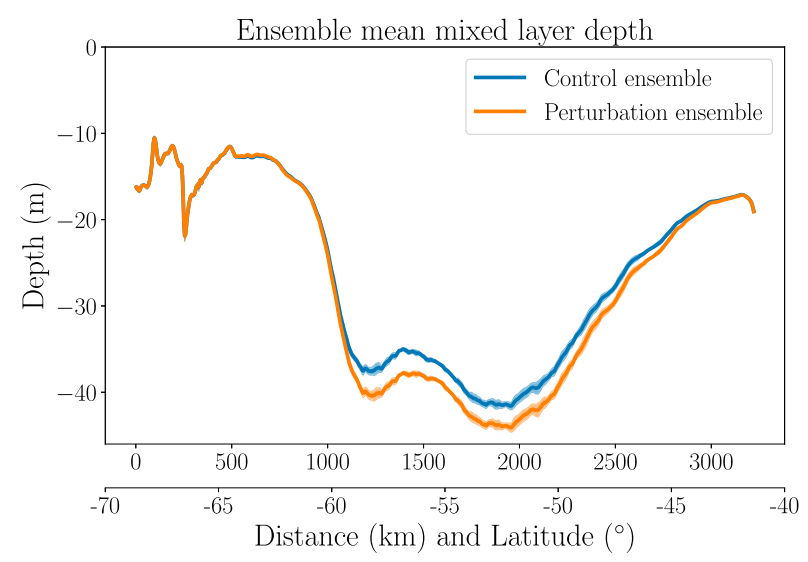

FIG. 5. Zonal-mean, ensemble-mean mixed layer depth from our idealized channel model, 1 month after applying the surface forcing perturbations. The mixed layer is deeper in the perturbation ensemble due to enhanced near surface mixing caused by the strengthened zonal wind. Shading indicates the standard error of the mean, calculated as the standard deviation of the ensemble divided by the square root of 6 , the number of ensemble members.

We begin by analyzing ensembles of idealized channel model simulations. After spinning up to a statistical equilibrium, we create two ensembles, one to establish the control and the other the perturbation about the control. To create a member of the perturbation ensemble we restart the model from a checkpoint with altered summertime zonal winds, surface air temperature, and surface humidity that mimic atmospheric conditions during a summer with a SAM index of +1 (see Doddridge et al. (2019) for details of the perturbations). In our idealized model we represent only the strengthening of the zonal winds, neglecting the potential impact of a meridional shift (cf. Waugh et al. 2019). This means that we do not expect the channel model to reproduce the patch of surface warming seen in the observations (Fig. 3).

We use six snapshots from the control simulation as initial conditions for the perturbation ensemble members, with each set of initial conditions separated from the previous state by 1 year of model time. The control ensemble is created by using the same checkpoints, but continuing the simulation without altering the atmospheric fields. Averaging multiple ensemble members helps to reduce the impact of the vigorous mesoscale eddy field on our results.

One month after applying the wind perturbation the mixed layer is deeper and colder in the perturbation ensemble than the control ensemble (Figs. 5 and 6a) (cf. Sallée et al. 2010). The perturbation ensemble also exhibits a region of anomalous warmth just below the zonal-mean mixed layer depth (Fig. 6a). To identify the physical mechanisms responsible for the temperature anomalies shown in Fig. 6a), we construct heat budgets for the regions outlined by the colored rectangles. The mixed layer region is chosen to be the deepest horizontal slab wholly contained within the mixed layer, while the region below the mixed layer is chosen such that it covers the cold remnants of the previous year's winter water. This is motivated by the mechanism proposed by Purich et al. (2016) who describe these waters upwelling in to the mixed layer. The heat budgets close to a high degree of accuracy; the residuals are eight to nine orders of magnitude smaller than the leading order terms. Our heat budgets show that the negative temperature anomaly in the mixed layer and the positive temperature anomaly in the region below are both predominantly caused by enhanced vertical diffusion (Figs. 6b,c). Both horizontal and vertical advection contribute to the cooling in the mixed layer, suggesting that the advective mechanisms proposed by Ferreira et al. (2015) and Purich et al. (2016) are also active in this model. However, the advective contributions are approximately an order of magnitude smaller than the cooling due to vertical diffusion (Fig. 6b). The dominance of vertical mixing is further corroborated by the integrated ocean heat content anomalies, which are almost equal in magnitude (Fig. 7). During the first summer the anomalous cooling in the mixed layer is slightly larger than the magnitude of the anomalous warming below the zonal-mean mixed layer depth, consistent with a small cooling contribution from advection.

As expected, there is an anomalous flux of heat into the ocean through the surface (see supplementary information, Fig. S1 in the online supplemental material), which causes the total upper-ocean heat content anomaly to increase (green line, Fig. 7). During autumn, the mixed layer deepens and returns the anomalously warm water below the zonal-mean mixed layer depth to the surface. In conjunction with the anomalous surface heat fluxes, this causes the mixed layer to become anomalously warm during the winter months (blue line, Fig. 7) and reduces sea ice volume (red line, Fig. 7). We can convert the upper-ocean heat content anomaly into an ice volume anomaly equivalent using the latent heat of fusion for sea ice. The ice volume anomaly equivalent is approximately four times larger than the ice volume anomaly from the model (see supplementary information, Fig. S2), confirming that the ocean heat content anomaly is sufficient to explain the modeled decrease in sea ice volume.

Our idealized channel model fails to reproduce the transient increase in sea ice extent found by Doddridge and Marshall (2017) in the observations. This is likely due to the sea ice edge being too far south to be substantially affected by the anomalously cold SST; by the time the sea ice edge extends far enough north to interact with the SST anomaly, the mixed layer has become anomalously warm.

\section{Analysis of the GISS coupled climate model}

While the zonal-mean temperature anomalies in our idealized channel model have much in common with those found in the observations, both in pattern and amplitude, the idealized nature of that model raises questions about how widely applicable the results are. We therefore seek to test our proposed mechanism in another model, one that is global and fully coupled, with interactive atmosphere, ice, and ocean components. We use the most recent National Aeronautics and Space Administration (NASA) Goddard Institute for Space Studies (GISS) global coupled model, Model E2.1, in the configuration described by Doddridge et al. (2019). A major caveat is that due to the added complexity, this model is run at a much coarser resolution and mesoscale eddies are parameterized rather than explicitly resolved. The model includes a Gent-McWilliams style eddy parameterization (Gent and McWilliams 1990; Gent et al. 1995) with a flow-dependent variable eddy diffusivity. Further details of the model and our numerical 


\section{Channel Model}

a) Zonal mean temperature anomaly after one month

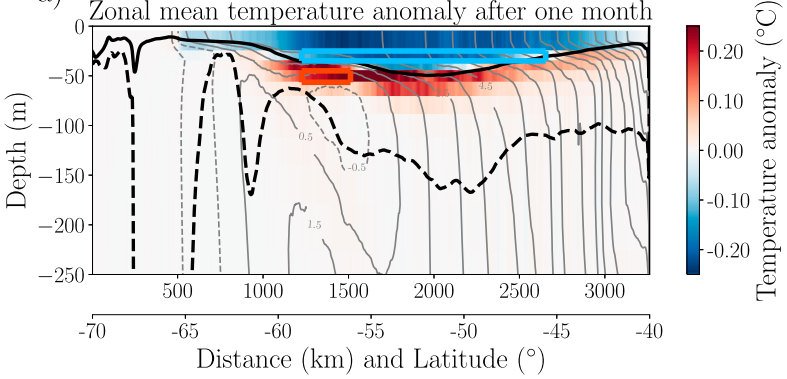

b)

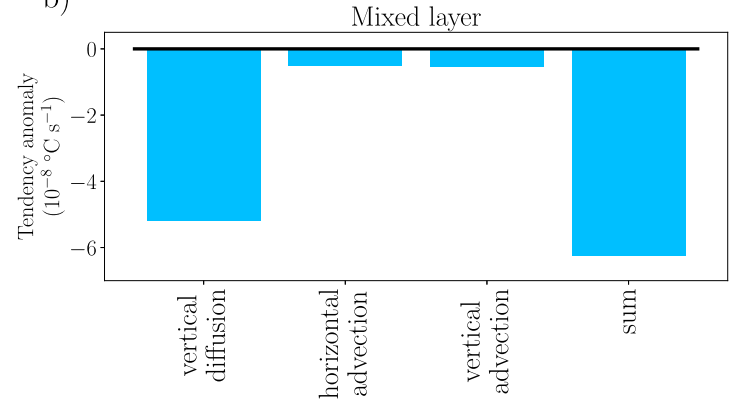

c)

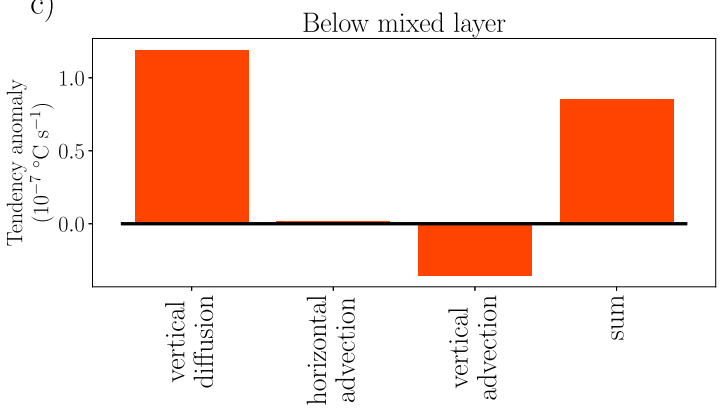

FIG. 6. Results from the eddying channel model 1 month after the wind perturbation is applied. (a) Zonal-mean temperature anomalies after 1 month (colors). The thin gray contours shows the climatological zonal-mean temperature field from the control ensemble in February at $\pm 0.5^{\circ}, \pm 1.5^{\circ} \mathrm{C}, \ldots$, with negative contours dashed. The thick black lines show the zonal-mean, ensemblemean mixed layer depth from the perturbation ensemble in February (solid) and September (dashed) of the first year after the perturbations are applied. (b) Zonal-mean heat budget for the region of the mixed layer outlined by the blue box in (a) showing that vertical diffusion dominates the cooling tendency. (c) Zonalmean heat budget for the region below the zonal-mean mixed layer depth outlined by the red box in (a) showing that vertical diffusion dominates the warming. The vertical advection contribution is consistent with the enhanced upwelling predicted by Purich et al. (2016). Horizontal diffusion makes no contribution to these budgets and is not plotted in (b) and (c).

setup can be found in Doddridge et al. (2019), Kelley et al. (2020), and Miller et al. (2020).

The climatology of the control configuration of this model closely resembles the observed climatology of the Southern Ocean; Fig. 8 shows the surface climatology of the model in the Southern Ocean for the summertime sea ice minimum in February (Fig. 8a) and the

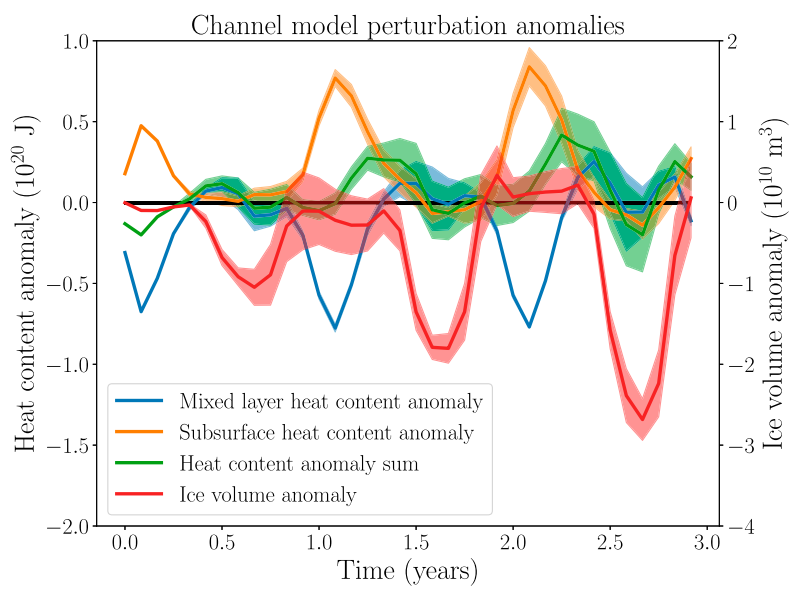

FIG. 7. Mixed layer heat content anomaly for the channel model (blue line), for the 100-m-thick region below the mixed layer (orange line), the sum of these two (green line), and sea ice volume anomaly (red line, right-hand axis). Shading represents plus and minus one standard deviation of the ensemble. The $x$ axis is time in years and the $y$ axis is either Joules (left axis) or cubic meters (right axis).

wintertime sea ice maximum in September (Fig. 8b). The seasonal cycle in sea ice extent is similar to the observed seasonal cycle; the summertime sea ice extent matches observations, while the wintertime extent is slightly too large (Fig. 8c). The zonal-mean SST is remarkably similar to the observed SST values (Fig. 8d). From an equilibrated preindustrial control simulation we spawn an ensemble of perturbation experiments by imposing a stratospheric ozone hole mimicking the conditions in the 1990s (see Doddridge et al. (2019) for details of the ozone hole perturbation). The imposed ozone depletion causes the summertime SAM to become anomalously positive and enhances the summertime westerly winds (Polvani et al. 2011). The perturbation is approximately +3 SAM units, roughly the same magnitude as the observed change between the 1960s and the 1990s. Once again we construct a control ensemble by combining the equivalent unperturbed simulations and define the anomaly as the difference between the two ensemble means. We will now use these ensembles to assess the influence of our mechanism in a global coupled model.

The zonal-mean temperature perturbation clearly shows a vertical dipole (Fig. 9a). Once again we define regions in and below the mixed layer. The mixed layer region is chosen to capture the largest horizontal slab contained wholly in the mixed layer, while the region below is chosen to encompass as much of the warming as possible while remaining below the region with cooling in the mixed layer. A heat budget for the mixed layer reveals that the cooling is largely driven by resolved horizontal advection, with diffusion and parameterized mesoscale advection making minor contributions (Fig. 9b). The warming is located below the zonal-mean mixed layer depth from the control ensemble, and our heat budget analysis reveals that diffusion is the largest contributor to this warming (Fig. 9c). Calculating the ocean heat content anomaly in the mixed layer and the region below the mixed layer shows that the cooling in the mixed layer is larger than the warming below, consistent with a substantial advective contribution to the surface cooling. Our heat budget reveals that horizontal advection is the dominant mechanism behind 
a)
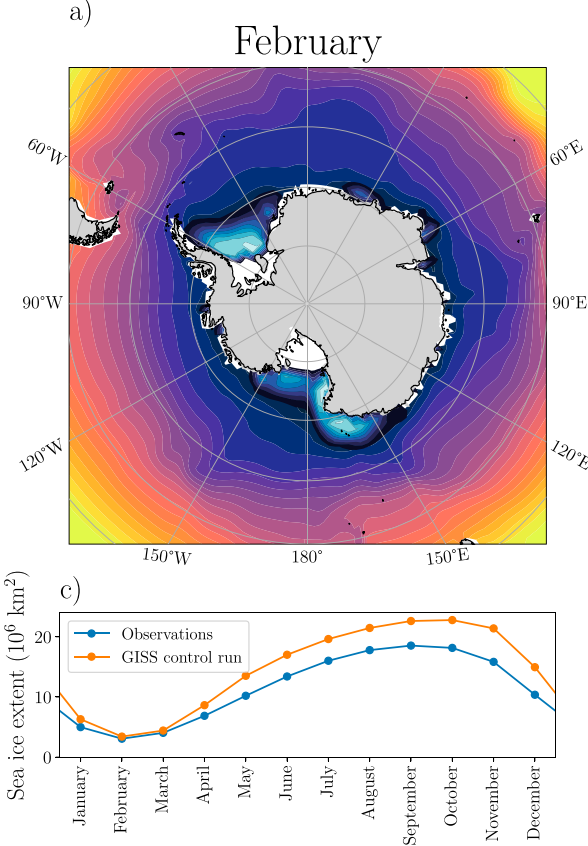

b)
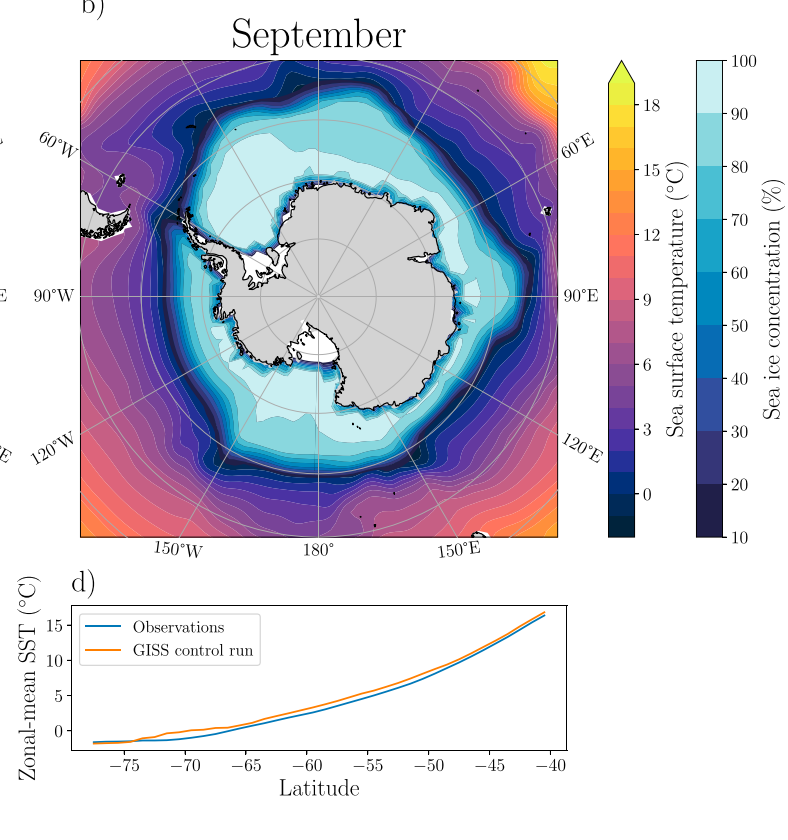

FIG. 8. Southern Ocean climatology from the control run of the GISS global coupled model and comparisons with observations. (a) SST and sea ice concentration in February, the summertime sea ice minimum. (b) SST and sea ice concentration in September, the wintertime sea ice maximum. (c) Climatological sea ice extent from the control run and the National Snow and Ice Data Center Sea Ice Index, version 3 (Fetterer et al. 2017). The GISS model matches the summertime extent, but the wintertime extent is slightly larger than observed. (d) Zonal mean of the climatological SST in February from the GISS control run and National Oceanic and Atmospheric Administration Optimum Interpolation SST, version 2.1 (Banzon et al. 2020). The model accurately reproduces both the mean SST and the meridional gradient over the Southern Ocean.

the surface cooling (Fig. 9b), which is consistent with the Ekman transport mechanism proposed by Ferreira et al. (2015) and Kostov et al. (2017).

The multiyear evolution of anomalies in the mixed layer ocean heat content, subsurface ocean heat content, and sea ice volume is shown in Fig. 10. At the beginning of each year, we observe an increase in subsurface heat content, which is consistent with our proposed vertical mixing mechanism. At the same time, we also see a large negative heat content anomaly in the mixed layer. The fact that the surface negative anomaly is larger than the subsurface positive anomaly is consistent with horizontal advection making a substantial contribution to mixed layer cooling, as shown in the heat budgets in Fig. 9. During the first, third, and fourth years, there is an anomalous decrease in sea ice volume toward the end of the year (late winter through to early summer), consistent with the reemergence of heat sequestered in the subsurface ocean. During the second year, the maximum negative sea ice volume anomaly occurs earlier in the year, suggesting that even with our ensemble averaging and imposed ozone perturbation, interannual variability can alter the timing of the sea ice volume anomaly.

To allow for easier comparison with the observational analysis in section 3 and Doddridge and Marshall (2017), we will now switch from analyzing differences between the control and perturbation ensembles to performing regression analyses on the control ensemble. This will allow for a more direct comparison with the observational results in Fig. 3. We begin by defining an analogous SAM index to the observational index from Marshall (2003). We then compute lagged linear correlations between this SAM index and the zonal-mean temperature field. The predicted zonal-mean temperature anomaly from a +1 SAM is shown in Fig. 11a. Once again we define two regions: one encompasses the cooling in the mixed layer, the other captures the subsurface warming. The ocean heat content anomalies calculated from the temperature changes within these two regions are plotted in Fig. 11b, and show that the cooling in the mixed layer is substantially larger than the warming below. The difference between the two heat content anomalies is consistent with the heat budget analysis that showed advection played a substantial role in cooling the mixed layer (Fig. 9b). To assess the sea ice response to SAM perturbations we regress sea ice area and sea ice volume against the summertime SAM index. We find a transient increase in both area and volume that peaks in May, following which the area anomaly decreases to zero and the volume anomaly becomes negative (Fig. 11c). Our analysis suggests that positive perturbations to the summertime SAM may reduce sea ice volume at the wintertime peak in sea ice. However, the lack of statistical significance means that we are unable to draw robust conclusions about the change in sea ice volume from these simulations.

\section{Discussion and conclusions}

We have proposed a new mechanism through which summertime wind perturbations can affect ocean temperature and 


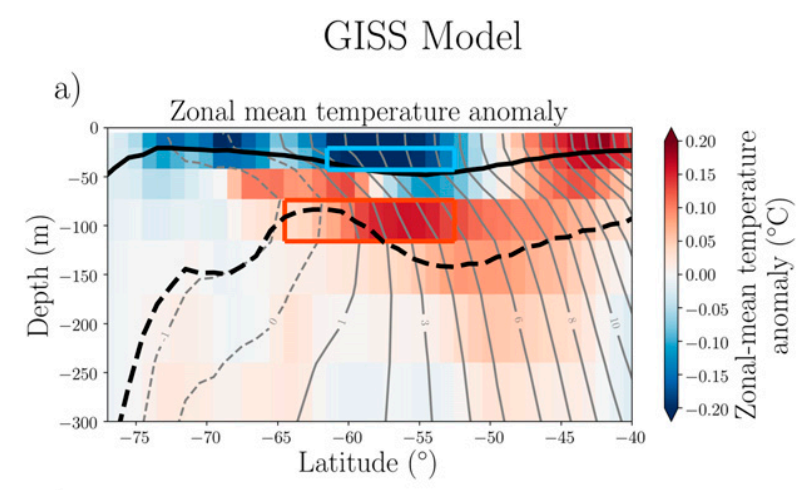

b)

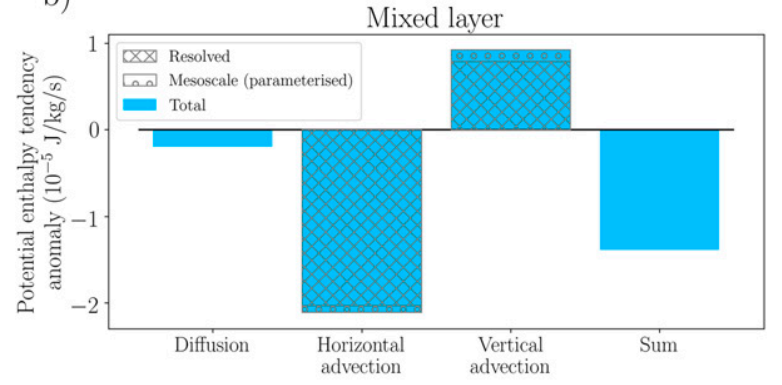

c)

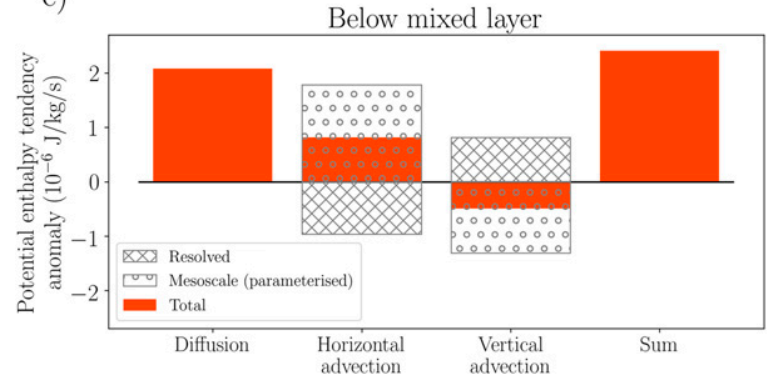

FIG. 9. (a) Zonal-mean temperature anomaly in the GISS model in February of the second year of the simulation. The gray contours show the climatological February temperature field from the control ensemble with contours at $0^{\circ}, \pm 1^{\circ}, \pm 2^{\circ} \mathrm{C}, \ldots$; negative and zero contours are dashed. The black lines represents the zonal-mean mixed layer depth from the perturbation ensemble in February (solid) and September (dashed) of the second year of the perturbation simulation. (b) Zonal-mean anomalous heat budget for a region in the mixed layer in February of the second year, shown by the blue rectangle in (a). Resolved horizontal advection makes the largest contribution to the anomalous cooling, with parameterized horizontal mesoscale advection and anomalous diffusion both making minor contributions to the cooling. (c) Zonal-mean anomalous heat budget for a region below the zonal-mean mixed layer depth in February of the second year. The region is shown by the red rectangle in (a). Mixing is largely responsible for the anomalous warming. Anomalous horizontal advection makes a moderate contribution to the warming, while anomalous vertical advection acts to cool this region. [Note that the vertical scale in (c) is an order of magnitude smaller than (b).]

sea ice over a seasonal time scale. According to our mechanism, strengthened summertime winds lead to anomalous vertical mixing, which cools the mixed layer and warms the ocean just beneath the mixed layer. Due to the anomalously cold sea

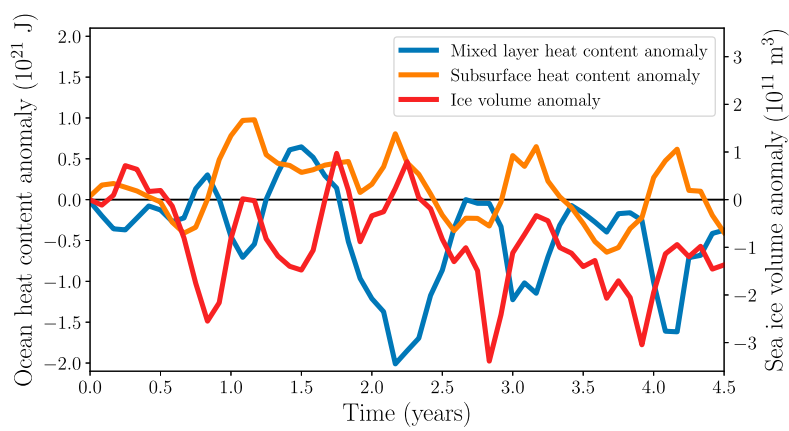

FIG. 10. Ocean heat content anomalies and sea ice volume anomalies in the GISS simulations from the first 4 years after the ozone perturbation is applied. Opposite-signed ocean heat content anomalies are consistent with our proposed vertical mixing mechanism, as is the decrease in sea ice volume near the end of the first, third, and fourth years. The anomalies are defined as the difference between the ensemble mean of the perturbation ensemble and the control ensemble.

surface, anomalous air-sea heat fluxes transfer additional heat into the surface ocean. As the mixed layer deepens during the autumn months, the combined effect of the anomalous air-sea heat fluxes and entrainment of anomalously warm subsurface water causes the mixed layer to become anomalously warm. This would likely lead to a reduction in sea ice during the winter months, either in ice volume, ice extent, or both.

It has previously been proposed that the surface cooling in response to strengthened westerly winds is primarily due to horizontal advection (Ferreira et al. 2015) or vertical advection (Purich et al. 2016). Our analysis of the observations suggests that enhanced vertical diffusion plays the leading role in creating both the cold SST anomaly and the warm subsurface temperature anomaly. However, due to large uncertainties in our results we are unable to rule out an advective contribution to the observed surface cooling signal. Our idealized channel model also supports a mixing based mechanism; the heat budget (Fig. 6b) clearly shows that anomalous vertical mixing is the dominant cause of the cold SST anomaly, with only minor contributions from both horizontal and vertical advection. This enhanced vertical mixing is also responsible for subsurface warming. In our global coupled model the mixed layer cooling is mostly due to horizontal advection, with only a small contribution from mixing, but the subsurface warming is almost entirely driven by enhanced vertical mixing. Because of the uncertainty in our results, we must conclude that, as far as the cold SST anomaly is concerned, the relative importance of our proposed mixing-based mechanism and the previously proposed advective mechanisms (Ferreira et al. 2015; Purich et al. 2016) is model dependent. The physical mechanisms responsible for this model dependence remain uncertain. It is likely that horizontal and vertical resolution play a central role, but it is also clear that even modest changes to parameter values can drastically alter the response within a single model. For example, when examining the decadal response to an ozone perturbation Seviour et al. (2019) showed that it is possible to reproduce the intermodel spread in responses by varying one 
a)

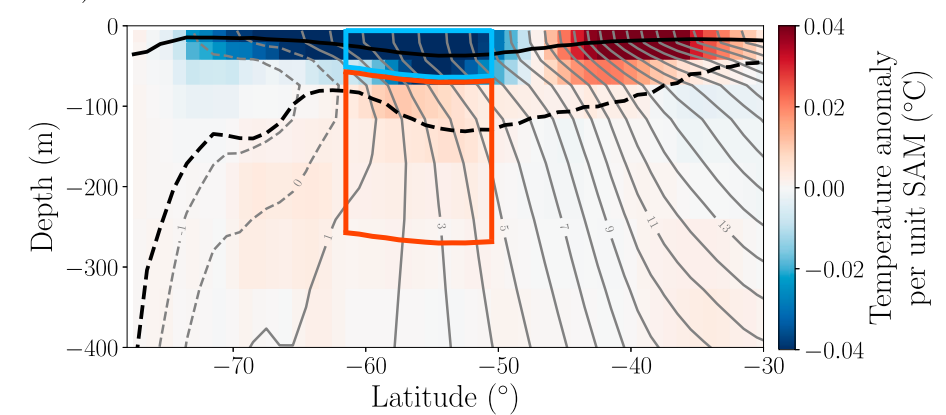

b)
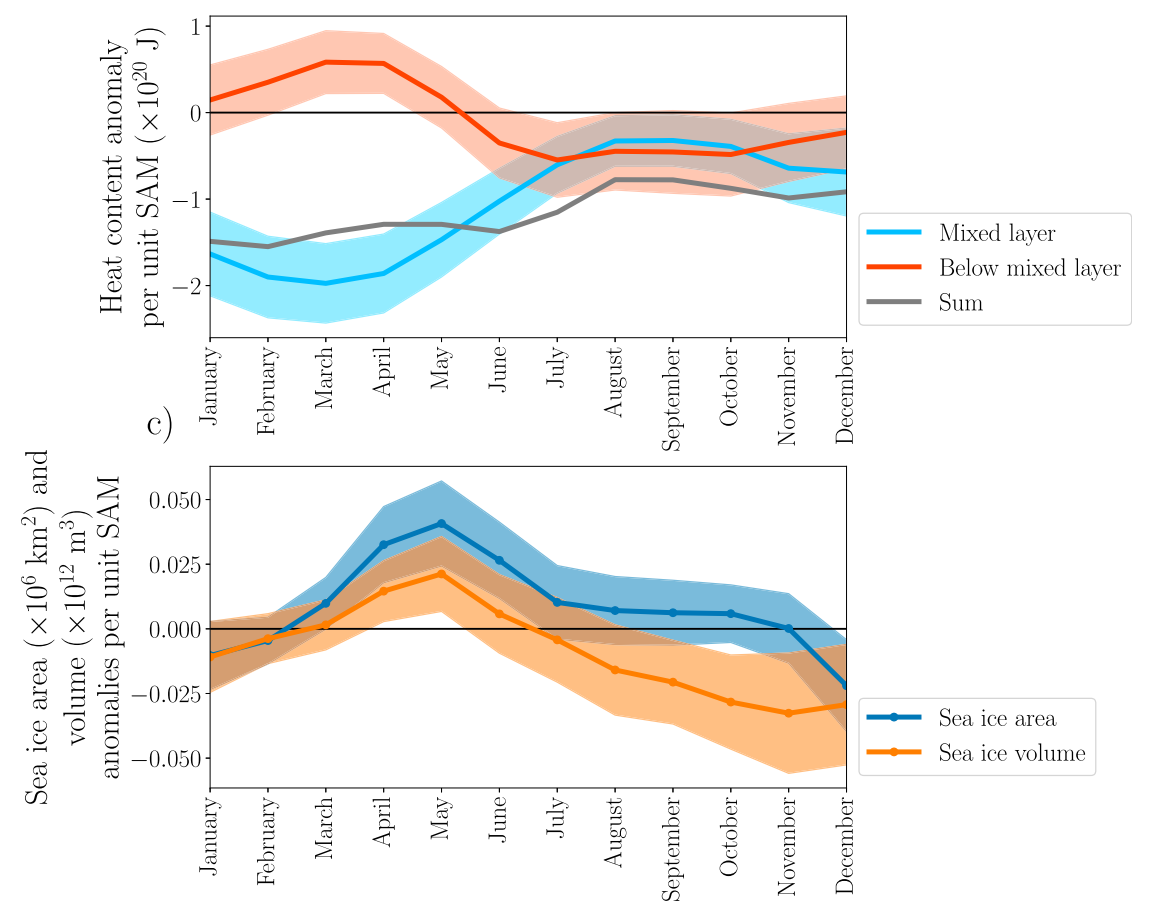

FIG. 11. Correlations between SAM and other model fields from the GISS control simulation. (a) Zonal-mean February temperature anomaly per unit DJF SAM. Gray contours show climatological zonal-mean temperature field in February with contours at $0^{\circ}, \pm 1^{\circ}, \pm 2^{\circ} \mathrm{C}, \ldots$; negative and zero contours are dashed. Black lines represent climatological zonal-mean mixed layer depth in February (solid) and September (dashed) from the control ensemble. (b) Ocean heat content anomalies calculated using the zonal-mean temperature perturbations and regions shown in (a). Blue line represents mixed layer box and red line represents box below mixed layer. Consistent with the diagnostics in Fig. 9, the sum of the two heat content anomalies is negative (gray line), showing that vertical redistribution is not the only process cooling the mixed layer. (c) The sea ice area (blue) and volume (orange) anomalies per unit SAM. Both show a transient increase, but only sea ice volume shows a reduction in the following winter. After applying a Bonferroni correction none of the regression coefficients are statistically discernible from zero.

subgridscale mixing parameter in a single model. Given the observational uncertainty and model dependence, it is difficult to conclusively state which mechanism is most important for the observed cold SST anomalies in the Southern Ocean. That said, we lend strong credence to the highly resolved channel calculations presented here-because the higher horizontal and vertical resolution means that the relevant dynamics is better resolved-and believe that enhanced vertical diffusion is likely more important than either horizontal or vertical advection. While our observational analysis is consistent with the conclusion that enhanced vertical mixing is the dominant mechanism driving these temperature anomalies, the uncertainties are too large to rule out an advective contribution. Future work, including the analysis of high-resolution global simulations, will hopefully provide greater clarity on the relative importance of the advective and mixing based mechanisms. 
Our observational analysis and our coupled global model both show that the summertime SAM has little impact on the wintertime sea ice extent. However, both our idealized channel model and our global coupled model show a reduction in sea ice volume in the winter following anomalously strong summertime westerlies. These results suggest that sea ice volume is more sensitive to summertime winds than sea ice extent. Unfortunately, we are unable to assess the relationship between summertime winds and sea ice volume in the observations due to the lack of a long-term time series for sea ice volume in the Southern Ocean. If, as our modeling results suggest, stronger summertime westerlies do cause a reduction in sea ice volume in the following winter, then a positive DJF SAM may precondition sea ice for a rapid retreat in the following spring. Indeed, there was a remarkable reduction in sea ice extent observed in the austral spring of 2016 (September-November) (Jones et al. 2016; Scambos and Stammerjohn 2018; Parkinson 2019), which followed an unusually large and positive SAM in the summer of 2015 that may have preconditioned Antarctic sea ice for the rapid springtime retreat the following year. That said, the 2016 decline has been linked to numerous factors including anomalous meridional winds and heat advection in the atmosphere (Schlosser et al. 2018), El Niño (Stuecker et al. 2017), the Interdecadal Pacific Oscillation (Meehl et al. 2019), tropical convection in the Indian and western Pacific Oceans (Wang et al. 2019), and to the SAM (Doddridge and Marshall 2017). The breadth of proposed explanations is testament to the complexity of the southern cryosphere. Exploring the contribution of our mechanism to sea ice changes in specific years or locations presents an exciting avenue for future work.

Through our proposed mechanism, enhanced summertime winds drive anomalous near-surface diapycnal mixing. According to Sloyan et al. (2010), summertime diapycnal mixing near the Subantarctic Front preconditions the ocean for the rapid development of deep mixed layers and efficient formation of Subantarctic Mode Water (SAMW) and Antarctic Intermediate Water (AAIW). Our mechanism may therefore increase the volume of SAMW and AAIW formed (cf. Gao et al. 2018). Further analysis of the role of summertime wind anomalies on the formation of SAMW and AAIW are beyond the scope of this contribution.

In conclusion, we have presented a novel mechanism that predicts a nonmonotonic SST response to summertime wind perturbations: initially the sea surface cools before warming in the winter months as heat that was sequestered below the surface is returned to the surface mixed layer. Our mechanism predicts that enhanced summertime westerlies increase sea ice cover during the autumn and reduce sea ice volume during winter; predictions that are supported by our modeling studies and observational analysis.

Acknowledgments. We are grateful to three anonymous reviewers for their feedback and guidance. Their input has greatly improved this manuscript. We thank Alex Haumann for helpful comments on an earlier draft. E. Doddridge acknowledges support from the NSF's Antarctic program. J. Marshall acknowledges support from the MIT-GISS collaborative agreement, the NASA Physical Oceanography Program, and the NSF Polar Antarctic Program. H. Song is supported by Yonsei University Research Fund (2018-22-0053) and National Research Foundation of Korea (NRF) grant funded by Korea government (MSIST) (NRF-2019R1C1C1003663).
This project received grant funding from the Australian Government as part of the Antarctic Science Collaboration Initiative program. The Australian Antarctic Program Partnership is led by the University of Tasmania, and includes the Australian Antarctic Division, CSIRO Oceans and Atmosphere, Geoscience Australia, the Bureau of Meteorology, the Tasmanian State Government, and Australia's Integrated Marine Observing System. Climate modeling at NASA-GISS is supported by the NASA Modeling, Analysis, and Prediction program. Computational resources for the E2.1 simulations in this study were provided by the NASA High-End Computing Program through the NASA Center for Climate Simulation (NCCS) at Goddard Space Flight Center.

Data availability statement. All observational datasets used can be obtained by following the directions in the cited articles. Model configurations are described in detail in the text and cited articles. Due to the expense of publicly hosting large datasets, the model output is not publicly available. Interested readers should contact the corresponding author for further information or access.

\section{REFERENCES}

Abernathey, R. P., I. Cerovecki, P. R. Holland, E. Newsom, M. Mazloff, and L. D. Talley, 2016: Water-mass transformation by sea ice in the upper branch of the Southern Ocean overturning. Nat. Geosci., 9 , 596-601, https://doi.org/10.1038/ngeo2749.

Banzon, V., T. M. Smith, M. Steele, B. Huang, and H.-M. Zhang, 2020: Improved estimation of Proxy sea surface temperature in the Arctic. J. Atmos. Oceanic Technol., 37, 341-349, https:// doi.org/10.1175/JTECH-D-19-0177.1.

Dee, D. P., and Coauthors, 2011: The ERA-Interim reanalysis: Configuration and performance of the data assimilation system. Quart. J. Roy. Meteor. Soc., 137, 553-597, https://doi.org/10.1002/qj.828.

Doddridge, E. W., and J. C. Marshall, 2017: Modulation of the seasonal cycle of Antarctic sea ice extent related to the Southern Annular Mode. Geophys. Res. Lett., 44, 9761-9768, https://doi.org/10.1002/2017GL074319.

_, J. Marshall, H. Song, J.-M. Campin, M. Kelley, and L. Nazarenko, 2019: Eddy compensation dampens Southern Ocean sea surface temperature response to westerly wind trends. Geophys. Res. Lett., 46, 4365-4377, https://doi.org/10.1029/2019GL082758.

Doney, S. C., and Coauthors, 2004: Evaluating global ocean carbon models: The importance of realistic physics. Global Biogeochem. Cycles, 18, GB3017, https://doi.org/10.1029/2003GB002150.

Ferreira, D., J. C. Marshall, C. M. Bitz, S. Solomon, and A. Plumb, 2015: Antarctic ocean and sea ice response to ozone depletion: A two-time-scale problem. J. Climate, 28, 1206-1226, https:// doi.org/10.1175/JCLI-D-14-00313.1.

Fetterer, F., K. Knowles, W. Meier, M. Savoie, and A. Windnagel, 2017: Sea Ice Index, Version 3 [south]. National Snow and Ice Data Center, Boulder, CO, https://doi.org/10.7265/N5K072F8

Furuichi, N., T. Hibiya, and Y. Niwa, 2008: Model-predicted distribution of wind-induced internal wave energy in the world's oceans. J. Geophys. Res., 113, C09034, https://doi.org/10.1029/2008JC004768.

Gao, L., S. R. Rintoul, and W. Yu, 2018: Recent wind-driven change in Subantarctic Mode Water and its impact on ocean heat storage. Nat. Climate Change, 8, 58-63, https://doi.org/ 10.1038/s41558-017-0022-8.

Gent, P. R., and J. C. McWilliams, 1990: Isopycnal mixing in ocean circulation models. J. Phys. Oceanogr., 20, 150-155, https://doi.org/ 10.1175/1520-0485(1990)020<0150:IMIOCM >2.0.CO;2. 
— J. Willebrand, T. J. McDougall, and J. C. McWilliams, 1995: Parameterizing eddy-induced tracer transports in ocean circulation models. J. Phys. Oceanogr., 25, 463-474, https://oi.org/ 10.1175/1520-0485(1995)025<0463:PEITTI >2.0.CO;2.

Gong, D., and S. Wang, 1999: Definition of Antarctic oscillation index. Geophys. Res. Lett., 26, 459-462, https://doi.org/ 10.1029/1999GL900003.

Haumann, F. A., N. Gruber, M. Münnich, I. Frenger, and S. Kern, 2016: Sea-ice transport driving Southern Ocean salinity and its recent trends. Nature, 537, 89-92, https://doi.org/10.1038/ nature19101.

Hausmann, U., A. Czaja, and J. C. Marshall, 2016: Estimates of airsea feedbacks on sea surface temperature anomalies in the Southern Ocean. J. Climate, 29, 439-454, https://doi.org/ 10.1175/JCLI-D-15-0015.1.

$\longrightarrow, \ldots$, and — 2017: Mechanisms controlling the SST air-sea heat flux feedback and its dependence on spatial scale. Climate Dyn., 48, 1297-1307, https://doi.org/10.1007/s00382-016-3142-3.

Holte, J., L. D. Talley, J. Gilson, and D. Roemmich, 2017: An Argo mixed layer climatology and database. Geophys. Res. Lett., 44, 5618-5626, https://doi.org/10.1002/2017GL073426.

Hoyer, S., and J. J. Hamman, 2017: xarray: N-D labeled arrays and datasets in Python. J. Open Res. Software, 5, 1-6, https:// doi.org/10.5334/jors.148.

Hunter, J. D., 2007: Matplotlib: A 2D graphics environment. Comput. Sci. Eng., 9, 90-95, https://doi.org/10.1109/ MCSE.2007.55.

Jones, J. M., and Coauthors, 2016: Assessing recent trends in highlatitude Southern Hemisphere surface climate. Nat. Climate Change, 6, 917-926, https://doi.org/10.1038/nclimate3103.

Kara, A. B., P. A. Rochford, and H. E. Hurlburt, 2000: An optimal definition for ocean mixed layer depth. J. Geophys. Res., 105, 16 803-16 821, https://doi.org/10.1029/2000JC900072.

Kelley, M., and Coauthors, 2020: GISS-E2.1: Configurations and climatology. J. Adv. Model. Earth Syst., 12, e2019MS002025, https://doi.org/10.1029/2019MS002025.

Klocker, A., 2018: Opening the window to the Southern Ocean: The role of jet dynamics. Sci. Adv., 4, eaao4719, https:// doi.org/10.1126/sciadv.aao4719.

Kluyver, T., and Coauthors, 2016: Jupyter Notebooks-A publishing format for reproducible computational workflows. Positioning and Power in Academic Publishing: Players, Agents, and Agendas, F. Loizides and B. Schmidt, Eds., IOS Press, 87-90.

Kostov, Y., J. C. Marshall, U. Hausmann, K. C. Armour, D. Ferreira, and M. M. Holland, 2017: Fast and slow responses of Southern Ocean sea surface temperature to SAM in coupled climate models. Climate Dyn., 48, 1595-1609, https:// doi.org/10.1007/s00382-016-3162-z.

Large, W. G., and S. G. Yeager, 2004: Diurnal to decadal global forcing for ocean and sea-ice models: The data sets and flux climatologies. NCAR Tech. Note NCAR/TN-460+STR, 105 pp., https://doi.org/10.5065/D6KK98Q6.

Losch, M., D. Menemenlis, J. M. Campin, P. Heimbach, and C. Hill, 2010: On the formulation of sea-ice models. Part I: Effects of different solver implementations and parameterizations. Ocean Modell., 33, 129-144, https://doi.org/10.1016/ j.ocemod.2009.12.008.

Marshall, D. P., 1997: Subduction of water masses in an eddying ocean. J. Mar. Res., 55, 201-222, https://doi.org/10.1357/ 0022240973224373 .

Marshall, G. J., 2003: Trends in the southern annular mode from observations and reanalyses. J. Climate, 16, 4134-4143, https://doi.org/ 10.1175/1520-0442(2003)016<4134:TITSAM>2.0.CO;2.
Marshall, J. C., and T. Radko, 2003: Residual-mean solutions for the Antarctic Circumpolar Current and its associated overturning circulation. J. Phys. Oceanogr., 33, 2341-2354, https://doi.org/ 10.1175/1520-0485(2003)033<2341:RSFTAC $>2.0$.CO; 2 .

, and K. Speer, 2012: Closure of the meridional overturning circulation through Southern Ocean upwelling. Nat. Geosci., 5, 171-180, https://doi.org/10.1038/ngeo1391.

— A. Adcroft, C. Hill, L. Perelman, and C. Heisey, 1997a: A finite-volume, incompressible Navier-Stokes model for studies of the ocean on parallel computers. J. Geophys. Res., 102, 5753-5766, https://doi.org/10.1029/96JC02775.

_ C. Hill, L. Perelman, and A. Adcroft, 1997b: Hydrostatic, quasihydrostatic, and nonhydrostatic ocean modeling. J. Geophys. Res., 102, 5733-5752, https://doi.org/10.1029/96JC02776.

Meehl, G. A., J. M. Arblaster, C. T. Y. Chung, M. M. Holland, A. DuVivier, L. Thompson, D. Yang, and C. M. Bitz, 2019: Sustained ocean changes contributed to sudden Antarctic sea ice retreat in late 2016. Nat. Commun., 10, 14, https://doi.org/ 10.1038/s41467-018-07865-9.

Miller, R. L., and Coauthors, 2020: CMIP6 historical simulations (1850-2014) with GISS-E2.1. J. Adv. Model. Earth Syst., https://doi.org/10.1029/2019MS002034, in press.

Munday, D. R., and X. Zhai, 2017: The impact of atmospheric storminess on the sensitivity of Southern Ocean circulation to wind stress changes. Ocean Modell., 115, 14-26, https:// doi.org/10.1016/j.ocemod.2017.05.005.

— H. L. Johnson, and D. P. Marshall, 2013: Eddy saturation of equilibrated circumpolar currents. J. Phys. Oceanogr., 43, 507532, https://doi.org/10.1175/JPO-D-12-095.1.

Munk, W., and C. Wunsch, 1998: Abyssal recipes II: Energetics of tidal and wind mixing. Deep-Sea Res. I, 45, 1977-2010, https:// doi.org/10.1016/S0967-0637(98)00070-3.

Panassa, E., C. Völker, D. Wolf-Gladrow, and J. Hauck, 2018: Drivers of interannual variability of summer mixed layer depth in the Southern Ocean between 2002-2011. J. Geophys. Res. Oceans, 123, 5077-5090, https://doi.org/10.1029/2018JC013901.

Parkinson, C. L., 2019: A 40-y record reveals gradual Antarctic sea ice increases followed by decreases at rates far exceeding the rates seen in the Arctic. Proc. Natl. Acad. Sci. USA, 116, 14414-14423, https://doi.org/10.1073/pnas.1906556116.

Perez, F., and B. E. Granger, 2007: IPython: A system for interactive scientific computing. Comput. Sci. Eng., 9, 21-29, https://doi.org/10.1109/MCSE.2007.53.

Pollard, R. T., P. B. Rhines, and R. O. R. Y. Thompson, 1972: The deepening of the wind-mixed layer. Geophys. Fluid Dyn., $\mathbf{4}$, 381-404.

Polvani, L. M., D. W. Waugh, G. J. P. Correa, and S.-W. Son, 2011: Stratospheric ozone depletion: The main driver of twentieth-century atmospheric circulation changes in the Southern Hemisphere. J. Climate, 24, 795-812, https://doi.org/10.1175/2010JCLI3772.1.

Purich, A., W. Cai, M. H. England, and T. Cowan, 2016: Evidence for link between modelled trends in Antarctic sea ice and underestimated westerly wind changes. Nat. Commun., 7, 10409, https://doi.org/10.1038/ncomms10409.

Rath, W., R. J. Greatbatch, and X. Zhai, 2014: On the spatial and temporal distribution of near-inertial energy in the Southern Ocean. J. Geophys. Res. Oceans, 119, 359-376, https://doi.org/ 10.1002/2013JC009246.

Reynolds, R. W., N. A. Rayner, T. M. Smith, D. C. Stokes, and W. Wang, 2002: An improved in situ and satellite SST analysis for climate. J. Climate, 15, 1609-1625, https://doi.org/10.1175/ 1520-0442(2002)015<1609:AIISAS>2.0.CO;2. 
Roemmich, D., and J. Gilson, 2009: The 2004-2008 mean and annual cycle of temperature, salinity, and steric height in the global ocean from the Argo Program. Prog. Oceanogr., 82, 81100, https://doi.org/10.1016/j.pocean.2009.03.004.

Sallée, J.-B., K. G. Speer, and S. R. Rintoul, 2010: Zonally asymmetric response of the Southern Ocean mixed-layer depth to the southern annular mode. Nat. Geosci., 3, 273-279, https:// doi.org/10.1038/ngeo812.

Sarmiento, J. L., N. Gruber, M. A. Brzezinski, and J. P. Dunne, 2004: High-latitude controls of thermocline nutrients and low latitude biological productivity. Nature, 427, 56-60, https:// doi.org/10.1038/nature02127.

Scambos, T., and S. Stammerjohn, 2018: Antarctica [in "State of the Climate in 2017'']. Bull. Amer. Meteor. Soc., 99, 175-192.

Schlosser, E., F. A. Haumann, and M. N. Raphael, 2018: Atmospheric influences on the anomalous 2016 Antarctic sea ice decay. Cryosphere, 12, 1103-1119, https://doi.org/10.5194/tc-12-1103-2018.

Seviour, W. J., A. Gnanadesikan, D. Waugh, and M. A. Pradal, 2017: Transient response of the Southern Ocean to changing ozone: Regional responses and physical mechanisms. J. Climate, 30, 2463-2480, https://doi.org/10.1175/JCLI-D-16-0474.1.

— , and Coauthors, 2019: The Southern Ocean sea surface temperature response to ozone depletion: A multimodel comparison. J. Climate, 32, 5107-5121, https://doi.org/10.1175/ JCLI-D-19-0109.1.

Sloyan, B. M., L. D. Talley, T. K. Chereskin, R. Fine, and J. Holte, 2010: Antarctic Intermediate Water and Subantarctic Mode Water formation in the Southeast Pacific: The role of turbulent mixing. J. Phys. Oceanogr., 40, 1558-1574, https://doi.org/ 10.1175/2010JPO4114.1.

Song, H., J. Marshall, J. M. Campin, and D. J. McGillicuddy, 2019: Impact of near-inertial waves on vertical mixing and air-sea $\mathrm{CO}_{2}$ fluxes in the Southern Ocean. J. Geophys. Res. Oceans, 124, 4605-4617, https://doi.org/10.1029/2018JC014928.

Stuecker, M. F., C. M. Bitz, and K. C. Armour, 2017: Conditions leading to the unprecedented low Antarctic sea ice extent during the 2016 austral spring season. Geophys. Res. Lett., 44, 9008-9019, https://doi.org/10.1002/2017GL074691.

Swart, N. C., and J. C. Fyfe, 2012: Observed and simulated changes in the Southern Hemisphere surface westerly wind-stress.
Geophys. Res. Lett., 39, L16711, https://doi.org/10.1029/ 2012GL052810.

Thompson, D. W. J., and J. M. Wallace, 2000: Annular modes in the extratropical circulation. Part I: Month-to-Month variability. J. Climate, 13, 1000-1016, https://doi.org/10.1175/ 1520-0442(2000)013<1000:AMITEC > 2.0.CO;2.

—, S. Solomon, P. J. Kushner, M. H. England, K. M. Grise, and D. J. Karoly, 2011: Signatures of the Antarctic ozone hole in Southern Hemisphere surface climate change. Nat. Geosci., 4, 741-749, https://doi.org/10.1038/ngeo1296.

Vallis, G. K., 2006: Atmospheric and Oceanic Fluid Dynamics. Cambridge University Press, $745 \mathrm{pp}$.

Van Der Walt, S., S. C. Colbert, and G. Varoquaux, 2011: The NumPy array: A structure for efficient numerical computation. Comput. Sci. Eng., 13, 22-30, https://doi.org/10.1109/ MCSE.2011.37.

Wang, G., H. H. Hendon, J. M. Arblaster, E. P. Lim, S. Abhik, and P. van Rensch, 2019: Compounding tropical and stratospheric forcing of the record low Antarctic sea-ice in 2016. Nat. Commun., 10, 13, https://doi.org/10.1038/s41467-018-07689-7.

Waugh, D. W., A. M. Hogg, P. Spence, M. H. England, and T. W. Haine, 2019: Response of Southern Ocean ventilation to changes in midlatitude westerly winds. J. Climate, 32, 53455361, https://doi.org/10.1175/JCLI-D-19-0039.1.

Williams, N. L., and Coauthors, 2017: Calculating surface ocean $\mathrm{pCO}_{2}$ from biogeochemical Argo floats equipped with $\mathrm{pH}$ : An uncertainty analysis. Global Biogeochem. Cycles, 31, 591-604, https://doi.org/10.1002/2016GB005541.

Wunsch, C., 1998: The work done by the wind on the oceanic general circulation. J. Phys. Oceanogr., 28, 2332-2340, https://doi.org/ 10.1175/1520-0485(1998)028<2332:TWDBTW >2.0.CO;2.

— , and R. Ferrari, 2004: Vertical mixing, energy, and the general circulation of the oceans. Annu. Rev. Fluid Mech., 36, 281-314, https://doi.org/10.1146/annurev.fluid.36.050802.122121.

Zhai, X., R. J. Greatbatch, C. Eden, and T. Hibiya, 2009: On the loss of wind-induced near-inertial energy to turbulent mixing in the upper ocean. J. Phys. Oceanogr., 39, 3040-3045, https:// doi.org/10.1175/2009JPO4259.1. 